\title{
Geochemical and Strontium Isotope Characterization of Produced Waters from Marcellus Shale Natural Gas Extraction
}

\author{
Elizabeth C. Chapman, ${ }^{\dagger}$ Rosemary C. Capo, ${ }^{\dagger}$ Brian W. Stewart, ${ }^{*}{ }^{\dagger}$ Carl S. Kirby ${ }^{\ddagger}$ Richard W. Hammack, $^{\S}$ \\ Karl T. Schroeder, ${ }^{\S}$ and Harry M. Edenborn ${ }^{\S}$ \\ ${ }^{\dagger}$ Department of Geology and Planetary Science, University of Pittsburgh, Pittsburgh, Pennsylvania 15260, United States \\ ${ }^{\ddagger}$ Department of Geology, Bucknell University, Lewisburg, Pennsylvania 17837, United States \\ ${ }^{\S}$ National Energy Technology Laboratory, U.S. Department of Energy, 626 Cochrans Mill Road, Pittsburgh, Pennsylvania 15236, \\ United States
}

\section{Supporting Information}

ABSTRACT: Extraction of natural gas by hydraulic fracturing of the Middle Devonian Marcellus Shale, a major gas-bearing unit in the Appalachian Basin, results in significant quantities of produced water containing high total dissolved solids (TDS). We carried out a strontium (Sr) isotope investigation to determine the utility of $\mathrm{Sr}$ isotopes in identifying and quantifying the interaction of Marcellus Formation produced waters with other waters in the Appalachian Basin in the event of an accidental release, and to provide information about the source of the dissolved solids. Strontium isotopic ratios of Marcellus produced waters collected over a geographic range of $\sim 375 \mathrm{~km}$ from southwestern to northeastern Pennsylvania define a relatively narrow set of values $\left(\varepsilon_{\mathrm{Sr}}^{\mathrm{SW}}=+13.8\right.$ to +41.6 , where $\varepsilon_{\mathrm{Sr}}^{\mathrm{SW}}$ is the deviation of the ${ }^{87} \mathrm{Sr} /{ }^{86} \mathrm{Sr}$ ratio from that of seawater in parts per $\left.10^{4}\right)$; this isotopic range falls above that of Middle Devonian seawater, and is distinct from most western Pennsylvania acid mine drainage and Upper Devonian Venango Group oil and gas brines. The uniformity of the isotope ratios suggests a basin-wide source of dissolved solids with a component that is more radiogenic than seawater. Mixing models indicate that $\mathrm{Sr}$ isotope ratios can be used to sensitively differentiate between Marcellus Formation produced water and other potential sources of TDS into ground or surface waters.

\section{INTRODUCTION}

Development of shale gas in the Appalachian Basin Marcellus Formation, one of the world's largest natural gas plays, has increased dramatically with the application of horizontal drilling and hydraulic fracturing techniques, a process that uses 8-15 million liters of water for each well. ${ }^{1-3}$ Waters produced from the well comprise a portion of the fracturing fluid, an injected water solution including various chemicals used to facilitate the hydraulic fracturing, as well as possible formation brines. These produced waters have total dissolved solid (TDS) contents often exceeding $200000 \mathrm{mg} / \mathrm{L}$, with elevated levels of strontium $(\mathrm{Sr})$, bromide $\left(\mathrm{Br}^{-}\right)$, sodium $(\mathrm{Na})$, calcium $(\mathrm{Ca})$, barium $(\mathrm{Ba})$, and chloride $\left(\mathrm{Cl}^{-}\right)$, most likely from interaction with formation waters and/or salts in the producing formation. ${ }^{4}$ Currently, TDS is considered an EPA secondary drinking water contaminant at levels above $500 \mathrm{mg} / \mathrm{L}^{5}$

Deep injection is the least expensive method for disposing produced water, with most produced water in the U.S. being disposed in Class II injection wells that target formations with suitable porosity, permeability, and capacity. ${ }^{6}$ However, only limited opportunities for deep injection exist in the areas of Pennsylvania where Marcellus Formation gas development is most intense. In these areas, increasingly greater volumes of produced water are being reused to hydraulically fracture subsequent wells. Where reuse is not practical, produced water is either treated for surface discharge or transported to nearby states where deep injection capacity exists. ${ }^{6}$ The storage and transportation of produced water prior to reuse, treatment, or deep injection provide some opportunity for these waters to become commingled with surface water or shallow groundwater through spills or releases. Deeper groundwater also could be affected if the integrity of the well is compromised. ${ }^{7}$

Recent stream contamination events and produced water releases have highlighted the need for methods to distinguish between multiple fossil fuel-related and other sources of TDS. For example, in 2008, high levels of sulfate, chloride, and bromide-dominated TDS were measured in the Monongahela River in western Pennsylvania; the source of this contamination was determined to be outflows from wastewater treatment plants which process both coal mine water and Marcellus Formation produced water. ${ }^{8}$ Similarly, in 2009 a significant fish kill occurred in Dunkard Creek, a tributary of the Monongahela River that flows along the border between Greene County, PA, and Monongalia County, WV. This event was caused by a release of high-TDS water, the source of which is still under

Received: November 9, 2011

Revised: February 22, 2012

Accepted: February 24, 2012

Published: February 24, 2012 
debate. ${ }^{9,10}$ Additionally, a number of fracturing fluid, produced water, and brine releases have occurred at Marcellus Formation well pads, including three releases at a single pad in Susquehanna County, PA, in which fracturing fluid reached a tributary of Towanda Creek. ${ }^{11}$

Although typical Marcellus Formation produced waters are chemically distinct from streams and uncontaminated groundwater, few geochemical parameters can unambiguously distinguish among all possible sources in the event of a spill or leakage. In Pennsylvania, such sources can include abandoned mine drainage, fly ash impoundments, brines from abandoned oil and gas wells from formations shallower than the Marcellus, road salt, wastewater outflows and septic systems, and industrial discharges. Here we explore the application of strontium $(\mathrm{Sr})$ isotope ratios to address these issues.

The isotopic ratio of radiogenic strontium- $87\left({ }^{87} \mathrm{Sr}\right.$, produced by the decay of ${ }^{87} \mathrm{Rb}$ over geologic time) to the stable $\mathrm{Sr}$ isotopes ${ }^{84} \mathrm{Sr},{ }^{86} \mathrm{Sr}$, and ${ }^{88} \mathrm{Sr}$ has been shown to be an effective tracer of water-rock interactions and has been used to identify and quantify sources of groundwater constituents in areas impacted by human activity. ${ }^{12-17}$ Unlike stable isotopes of oxygen, hydrogen, and carbon, the isotope composition of $\mathrm{Sr}$ is not affected by evaporation (e.g., from holding ponds) or biological activity. For the isotope ratio of $\mathrm{Sr}$ (expressed as ${ }^{87} \mathrm{Sr} /{ }^{86} \mathrm{Sr}$ ) to be used successfully as a natural tracer in ground and surface waters, the isotope ratios of the potential endmembers must be distinct. If potential endmembers have distinct $\mathrm{Sr}$ isotopic ratios, $\mathrm{Sr}$ isotopes can be used as sensitive indicators of even minute amounts of contamination from brines, and potentially to identify waters interacting with rocks from specific stratigraphic units. ${ }^{18-20}$

In addition, understanding the sources of these salts and metals can be useful in designing drilling strategies and understanding heterogeneities in the producing unit. Many formation brines, including those of the Appalachian Basin, have been found to have a significant component of evaporated seawater. ${ }^{21-24}$ Conversely, the presence of lenticular salt deposits in a Marcellus core has led to the hypothesis that the high salinity originates from autochthonous salts. ${ }^{4}$ Strontium isotopes can also be used to understand the origin of salts in produced waters, i.e., to determine if salts are from evaporated seawater and to identify additional sources of dissolved constituents (e.g., carbonates, exchangeable sites on clays). We carried out an isotope study of Marcellus produced waters to (1) identify unique isotope "fingerprints" of Marcellus waters to aid in verification of safe disposal; and (2) determine the source of dissolved solids that are abundant and ubiquitous in Marcellus waters.

\section{METHODS}

Marcellus Produced Waters. Samples of hydraulic fracturing waters and waters produced during and after drilling from wellheads and impoundments from four counties across Pennsylvania (Figure 1) were obtained by DOE-NETL and Bucknell University. Some were collected as time series from the start of pumping, and others were collected from impoundments where they were being held prior to recycling or disposal. Samples BR-A1 through BR-A5 were produced waters collected from five wells in Bradford County; samples BR-A3, A4, and A5 had been recycled through several fracturing operations. Samples beginning with WE were collected from two closely spaced wells $(<1 \mathrm{~km}$ apart; designated by " $A$ " and " $B$ " in sample name) in Westmoreland

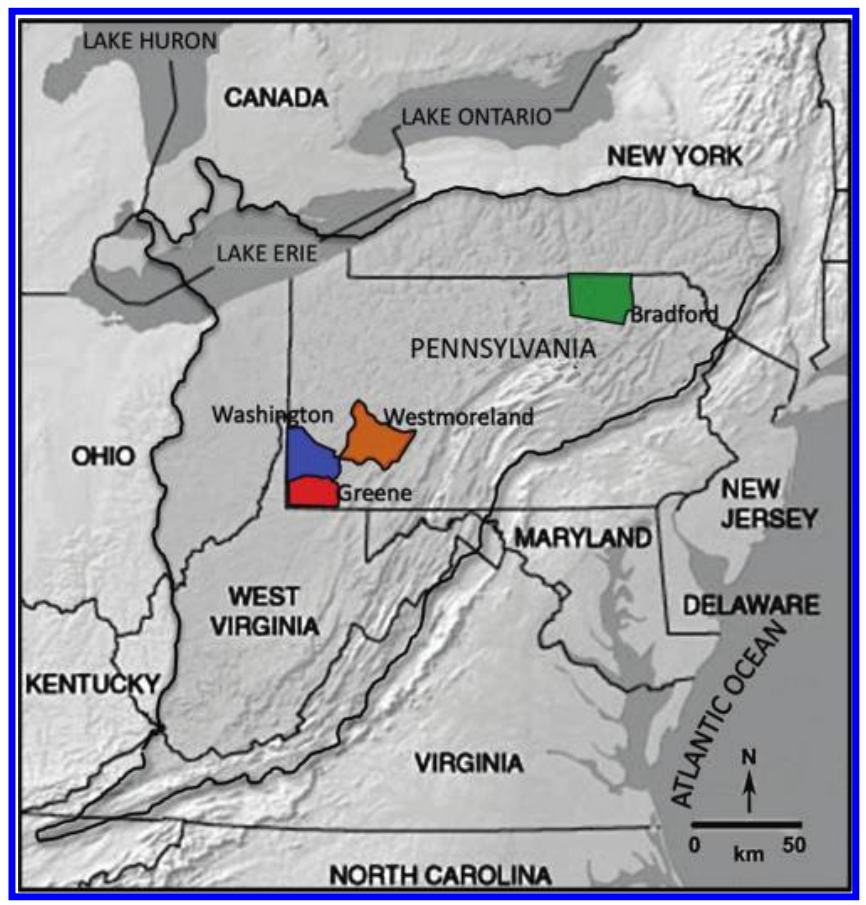

Figure 1. Map showing the extent of the Marcellus Formation (shaded), with the locations (indicated by county) of the samples reported in this study.

County, at the indicated number of days after the start of pumping. Samples labeled WA-B1-\# through WA-B3-\# were collected in Washington County from three different wastewater impoundments, at various depths (indicated by \#) below the water surface (Table 1). Samples WA-A11 through WAA30 were collected from a well in Washington County at the indicated number of days after the start of pumping. Samples beginning with GR were collected from a well in Greene County at the indicated number of days after the start of pumping; GR-AF is a sample of the water used to hydraulically fracture that well (fracturing fluid).

Coal Mine Drainage. Samples of coal mine drainage (acid, circumneutral, and net alkaline) from bituminous coals of the Pittsburgh Formation and Allegheny Group (Pittsburgh, Freeport, Kittanning, Clarion, and Brookville) were analyzed for $\mathrm{Sr}$ isotopes to compare with potential Marcellus produced water. Major element and Sr isotope geochemistry is presented in Supporting Information Table S1.

Analytical Methods. Samples were filtered to $<0.45 \mu \mathrm{m}$ and acidified with ultrapure concentrated nitric acid $\left(\mathrm{HNO}_{3}\right)$. Major and trace elements were analyzed by ICP-MS and ICPOES at DOE-NETL and Bucknell University. Strontium isotope preparation and analysis was carried out under clean $\mathrm{lab}$ conditions at University of Pittsburgh. Using $\mathrm{Sr}$ concentrations determined by ICP-OES, aliquots containing between 2 and $10 \mu \mathrm{g}$ of $\mathrm{Sr}$ were evaporated to dryness, redissolved in $6 \mathrm{~N}$ ultrapure $\mathrm{HNO}_{3}$, and eluted through columns containing Eichrom $\mathrm{Sr}$ resin to separate $\mathrm{Sr}$ from all other constituents in the sample. The eluted $\mathrm{Sr}$ was evaporated to dryness and redissolved in $2 \mathrm{~N}$ ultrapure $\mathrm{HNO}_{3}$. An aliquot containing approximately $500 \mathrm{ng}$ of $\mathrm{Sr}$ was evaporated onto a Re filament preloaded with a Ta oxide carrier agent. Strontium isotopes of the samples as well as the Sr standard SRM 987 were measured using a multidynamic method on a FinniganMAT 262 thermal ionization mass spectrometer. The average 
Table 1. Major Element and Strontium Isotope Data for Marcellus Produced Water Samples

\begin{tabular}{|c|c|c|c|c|c|c|c|c|c|c|c|}
\hline \multirow[b]{2}{*}{$\begin{array}{l}\text { sample/ } \\
\text { location }\end{array}$} & \multirow[b]{2}{*}{ description } & \multicolumn{7}{|c|}{$\mathrm{mg} / \mathrm{L}$} & \multirow[b]{2}{*}{$\begin{array}{l}\text { TDS } \\
\mathrm{g} / \mathrm{L}\end{array}$} & \multirow[b]{2}{*}{${ }^{87} \mathrm{Sr} /{ }^{86} \mathrm{Sr}{ }^{a}$} & \multirow[b]{2}{*}{$\varepsilon_{\mathrm{Sr}}^{\mathrm{SW} b}$} \\
\hline & & $\mathrm{Na}$ & $\mathrm{Ca}$ & $\mathrm{Mg}$ & $\mathrm{Fe}$ & $\mathrm{Sr}$ & $\mathrm{Ba}$ & $\mathrm{Cl}$ & & & \\
\hline \multicolumn{12}{|c|}{ Bradford Co., PA } \\
\hline BR-A1 & produced water & 30,400 & 6,120 & 538 & 117 & 1,970 & 5,490 & 77,000 & 109.5 & $0.710653 \pm 07$ & $20.93 \pm 0.10$ \\
\hline BR-A2 & produced water & 49,400 & 20,800 & 1,750 & 123 & 5,230 & 12,000 & 159,000 & 211.4 & $0.710270 \pm 10$ & $15.53 \pm 0.14$ \\
\hline BR-A3 & recycled prod. water & 41,900 & 11,300 & 1,110 & 73.7 & 3,340 & 7,820 & 68,000 & 154.1 & $0.710742 \pm 06$ & $22.18 \pm 0.08$ \\
\hline BR-A4 & recycled prod. water & 34,000 & 7,930 & 840 & 50.5 & 2,870 & 6,470 & 77,000 & 136.6 & $0.710757 \pm 08$ & $22.39 \pm 0.11$ \\
\hline BR-A5 & recycled prod. water & 27,600 & 7,050 & 726 & 55.3 & 2,600 & 5,860 & 73,000 & 120.9 & $0.710733 \pm 09$ & $22.05 \pm 0.13$ \\
\hline \multicolumn{12}{|c|}{ Westmoreland Co., PA } \\
\hline WE-A1.5 & prod. water, day 1.5 & $\mathrm{NA}^{c}$ & 349 & NA & NA & 46.0 & 70.0 & NA & 14.8 & $0.711992 \pm 06$ & $39.81 \pm 0.08$ \\
\hline WE-A2 & prod. water, day 2 & 2,792 & 624 & 43 & NA & 88.0 & 179 & 10,300 & 21.4 & $0.712013 \pm 10$ & $40.10 \pm 0.14$ \\
\hline WE-A4 & prod. water, day 4 & 11,747 & 2,278 & 217 & $\mathrm{NA}$ & 381 & 740 & 29,000 & 44.8 & $0.712036 \pm 10$ & $40.43 \pm 0.14$ \\
\hline WE-A5 & prod. water, day 5 & 14,216 & 2,880 & 254 & NA & 450 & 888 & 32,200 & 51.1 & $0.712027 \pm 10$ & $40.30 \pm 0.14$ \\
\hline WE-A7 & prod. water, day 7 & 18,288 & 3,938 & 381 & $\mathrm{NA}$ & 651 & 1,405 & 42,000 & 65.7 & $0.712044 \pm 06$ & $40.54 \pm 0.08$ \\
\hline WE-A12 & prod. water, day 12 & 23,928 & 5,603 & 518 & NA & 934 & 2,193 & 47,900 & 81.2 & $0.712013 \pm 08$ & $40.10 \pm 0.11$ \\
\hline WE-A15 & prod. water, day 15 & 24,820 & 6,292 & 629 & NA & 1,127 & 2,687 & 53,500 & 89.5 & $0.712019 \pm 10$ & $40.19 \pm 0.14$ \\
\hline WE-A29 & prod. water, day 29 & 26,297 & 6,236 & 671 & NA & 1,215 & 2,987 & 76,600 & 99.0 & $0.712091 \pm 07$ & $41.20 \pm 0.10$ \\
\hline WE-B3 & prod. water, day 3 & 9,901 & 1,239 & 694 & NA & 214 & 333 & 19,000 & 33.3 & $0.712076 \pm 11$ & $40.99 \pm 0.16$ \\
\hline WE-B5 & prod. water, day 5 & 16,704 & 2,782 & 376 & NA & 533 & 1,058 & 30,600 & 55.6 & $0.712108 \pm 07$ & $41.44 \pm 0.10$ \\
\hline WE-B7 & prod. water, day 7 & 18,288 & 3,900 & 490 & NA & 738 & 1,490 & 40,700 & 69.4 & $0.712088 \pm 08$ & $41.16 \pm 0.11$ \\
\hline WE-B9 & prod. water, day 9 & 18,510 & 4,627 & 559 & $\mathrm{NA}$ & 900 & 1,892 & 46,800 & 78.4 & $0.712108 \pm 08$ & $41.44 \pm 0.11$ \\
\hline WE-B13 & prod. water, day 13 & 22,437 & 5,749 & 211 & NA & 1,063 & 2,306 & 71,100 & 89.3 & $0.712117 \pm 09$ & $41.57 \pm 0.13$ \\
\hline WE-B18 & prod. water, day 18 & NA & 6,278 & NA & NA & 1,380 & 2,700 & NA & 98.1 & $0.712113 \pm 09$ & $41.51 \pm 0.13$ \\
\hline \multicolumn{12}{|c|}{ Washington Co., PA } \\
\hline WA-A11 & prod. water, day 11 & 32,500 & 12,278 & 1,267 & 38.6 & 1,393 & 151 & 88,500 & 136.2 & $0.711129 \pm 08$ & $27.64 \pm 0.11$ \\
\hline WA-A13 & prod. water, day 13 & 35,070 & 14,028 & 1,478 & 41.8 & 1,694 & 194 & 102,100 & 146.7 & $0.710988 \pm 10$ & $25.65 \pm 0.14$ \\
\hline WA-A15 & prod. water, day 15 & 37,100 & 15,269 & 1,632 & 17.3 & 1,832 & 253 & 107,300 & 153.4 & NA & \\
\hline WA-A17 & prod. water, day 17 & 38,530 & 15,875 & 1,671 & 21.6 & 1,872 & 296 & 102,600 & 156.7 & $0.711056 \pm 11$ & $26.61 \pm 0.16$ \\
\hline WA-A20 & prod. water, day 20 & 40,350 & 16,509 & 1,820 & 19.0 & 1,888 & 328 & 115,300 & 167.8 & $0.711088 \pm 09$ & $27.06 \pm 0.13$ \\
\hline WA-A25 & prod. water, day 25 & 46,260 & 17,612 & 1,896 & 15.6 & 2,045 & 349 & 116,100 & 168.4 & $0.711021 \pm 10$ & $26.12 \pm 0.14$ \\
\hline WA-A30 & prod. water, day 30 & 47,881 & 18,080 & 1,992 & NA & 2,151 & 379 & NA & 169.4 & $0.711076 \pm 08$ & $26.89 \pm 0.11$ \\
\hline WA-B1-8 & impound\#1, 8' depth & 20,310 & 8,682 & 880 & 18.7 & 1,192 & 176 & 59,600 & 108.0 & $0.710880 \pm 10$ & $24.13 \pm 0.14$ \\
\hline WA-B1-4 & impound\#1, 4' depth & 20,440 & 8,796 & 890 & 15.8 & 1,205 & 191 & 65,300 & 117.0 & $0.710905 \pm 10$ & $24.48 \pm 0.14$ \\
\hline WA-B2-9 & impound\#2, 9' depth & 20,510 & 8,779 & 859 & 5.12 & 1,277 & 389 & 59,400 & 110.7 & $0.710969 \pm 08$ & $25.38 \pm 0.11$ \\
\hline WA-B2-6 & impound\#2, 6' depth & 20,910 & 8,818 & 866 & 4.37 & 1,296 & 339 & 58,700 & 108.0 & $0.710954 \pm 10$ & $25.17 \pm 0.14$ \\
\hline WA-B3-10 & impound\#3, 10' depth & 12,890 & 5,674 & 570 & 0.067 & 795 & 10.5 & 36,700 & 71.4 & $0.710737 \pm 10$ & $22.11 \pm 0.14$ \\
\hline WA-B3-5 & impound\#3, 5' depth & 12,940 & 5,733 & 589 & 0.066 & 803 & 9.54 & 36,800 & 71.4 & $0.710722 \pm 09$ & $21.90 \pm 0.13$ \\
\hline \multicolumn{12}{|c|}{ Greene Co., PA } \\
\hline GR-AF & frac water & 20,923 & 4,377 & 567 & 16.0 & 1,389 & 393 & 41,900 & 88.7 & $0.710084 \pm 08$ & $12.90 \pm 0.11$ \\
\hline GR-A1 & prod. water, day 1 & 26,020 & 6,532 & 776 & 43.7 & 1,397 & 1,108 & 63,700 & 127.2 & $0.710988 \pm 08$ & $25.65 \pm 0.11$ \\
\hline GR-A2 & prod. water, day 2 & 30,100 & 7,903 & 828 & 44.9 & 1,823 & 1,560 & 65,000 & 138.8 & $0.710976 \pm 10$ & $25.48 \pm 0.14$ \\
\hline GR-A3 & prod. water, day 3 & 26,840 & 7,372 & 866 & 49.2 & 1,721 & 1,487 & 67,300 & 137.8 & $0.710957 \pm 07$ & $25.21 \pm 0.10$ \\
\hline GR-A4 & prod. water, day 4 & 30,910 & 8,874 & 755 & 38.1 & 2,009 & 1,756 & 70,200 & 146.2 & $0.710961 \pm 09$ & $25.27 \pm 0.13$ \\
\hline GR-A5 & prod. water, day 5 & 28,270 & 7,952 & 762 & 1.10 & 1,868 & 1,638 & 71,200 & 143.1 & $0.710975 \pm 08$ & $25.47 \pm 0.11$ \\
\hline GR-A7 & prod. water, day 7 & 32,800 & 8,786 & 841 & 26.6 & 2,415 & 962 & 81,900 & 157.0 & $0.710148 \pm 08$ & $13.80 \pm 0.11$ \\
\hline GR-A15 & prod. water, day 15 & 32,380 & 9,634 & 953 & 28.1 & 2,275 & 2,273 & 86,500 & 161.5 & $0.711160 \pm 09$ & $28.08 \pm 0.13$ \\
\hline GR-A20 & prod. water, day 20 & 34,520 & 10,390 & 976 & 36.1 & 2,484 & 2,525 & 87,700 & 188.2 & $0.711173 \pm 09$ & $28.26 \pm 0.13$ \\
\hline GR-A27 & prod. water, day 27 & NA & NA & NA & NA & NA & NA & NA & NA & $0.711183 \pm 41$ & $28.40 \pm 0.58$ \\
\hline
\end{tabular}

${ }^{87} \mathrm{Sr} /{ }^{86} \mathrm{Sr}$ ratio of SRM 987 over the period of these analyses was $0.710243 \pm 0.000017(n=45)$.

Strontium isotope ratios are presented using epsilon notation, where the ${ }^{87} \mathrm{Sr} /{ }^{86} \mathrm{Sr}$ ratio of the sample is normalized to the globally uniform ${ }^{87} \mathrm{Sr} /{ }^{86} \mathrm{Sr}$ ratio of present-day seawater:

$$
\varepsilon_{\mathrm{Sr}}^{\mathrm{SW}}=10^{4}\left(\frac{{ }^{87} \mathrm{Sr} /{ }^{86} \mathrm{Sr}_{\text {sample }}}{{ }^{87} \mathrm{Sr} /{ }^{86} \mathrm{Sr}_{\text {seawater }}}-1\right)
$$

Based on alternating measurements of SRM 987 and seawater $\left(n=23\right.$ for each), the offset between the two $\left({ }^{87} \mathrm{Sr} /{ }^{86} \mathrm{Sr}_{\text {SRM987 }}\right.$ $\left.{ }^{87} \mathrm{Sr} /{ }^{86} \mathrm{Sr}_{\text {seawater }}\right)$ is 0.001074 , leading to a corresponding seawater ${ }^{87} \mathrm{Sr} /{ }^{86} \mathrm{Sr}$ value of 0.709169 .

\section{RESULTS AND DISCUSSION}

Produced Water Dissolved Load. Major element data from the Pennsylvania produced waters reported here (Table 1 ) indicate that these waters share many of the characteristics 
previously reported for Marcellus Formation produced waters, ${ }^{4}$ including variable but generally high TDS (20000 to >200 000 $\mathrm{mg} / \mathrm{L}$ ), the predominance of $\mathrm{Na}$ and $\mathrm{Cl}$ in the dissolved load, and very high concentrations of $\mathrm{Ba}$ and $\mathrm{Sr}$ (up to 12000 and $5200 \mathrm{mg} / \mathrm{L}$, respectively). Chloride is largely balanced by $\mathrm{Na}^{+}$, with $\mathrm{Ca}^{2+}$ providing most of the remaining charge balance (Figure 2a). The wells and impoundment waters from

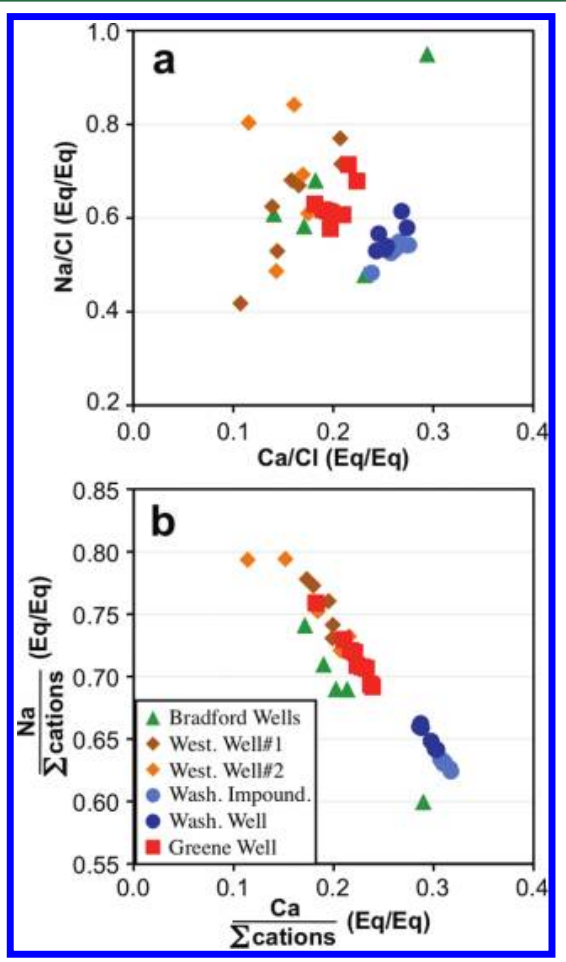

Figure 2. Variations in the chemical composition of Marcellus Formation produced water. (a) $\mathrm{Na} / \mathrm{Cl}$ ratios plotted against $\mathrm{Ca} / \mathrm{Cl}$ on an equivalent basis. $\mathrm{Na}$ and $\mathrm{Ca}$ are the dominant cations that together account for most of the $\mathrm{Cl}$ in produced waters, suggesting a source with both $\mathrm{NaCl}$ - and $\mathrm{CaCl}_{2}$-type salts or brines. (b) $\mathrm{Na}$ and $\mathrm{Ca}$ normalized to the sum of all cations, on an equivalent basis. The offset of the Bradford County samples (green triangles) from the rest of the trend reflects the very high concentrations of $\mathrm{Ba}$ and $\mathrm{Sr}$ in these waters.

Washington County have more Ca-rich compositions compared to the other produced waters. Comparison of $\mathrm{Na}$ and $\mathrm{Ca}$ to the sum of all cations (Figure $2 b$ ) indicates the importance of $\mathrm{Na}$ and $\mathrm{Ca}$ to the overall dissolved load. The offset of the Bradford County samples from this trend reflects the extremely high concentrations of $\mathrm{Sr}$ and $\mathrm{Ba}$ in these waters, which contribute significantly to the overall dissolved load. There are no clear geographic trends in concentration from the southwestern-most to the northeastern-most produced waters, although the Bradford County produced waters tend to have the highest concentrations of dissolved constituents, and the Westmoreland County waters tend to have the lowest.

Marcellus produced waters are known for their high $\mathrm{Ba}$ and Sr concentrations. ${ }^{4}$ Both of these are alkaline earth elements, with geochemical characteristics similar to those of $\mathrm{Ca}$ and magnesium $(\mathrm{Mg})$. When normalized to $\mathrm{Ca}$ to account for the large variations in $\mathrm{TDS}, \mathrm{Ba}$ and $\mathrm{Sr}$ show a positive correlation across the region, with only the Greene County well data diverging significantly from the trend (Figure 3a). However, data from each well or region fall within unique, non-

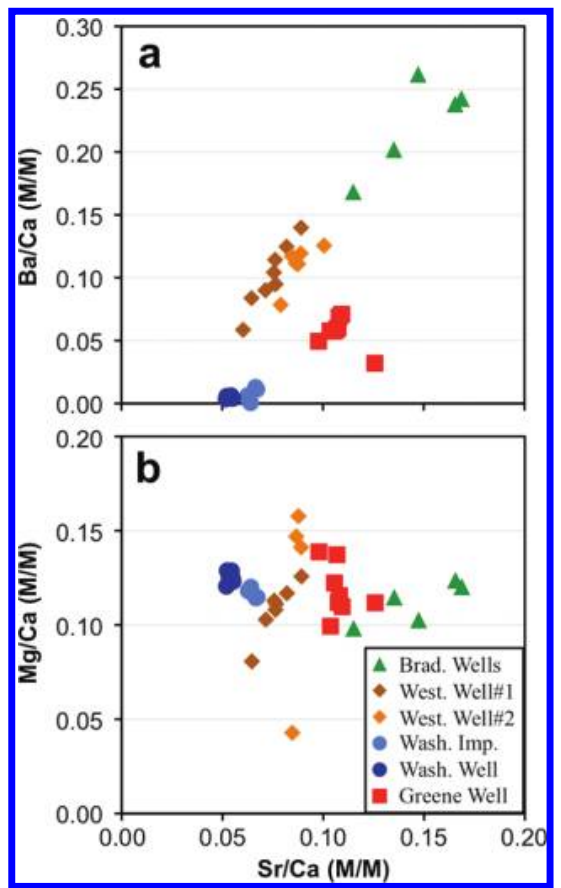

Figure 3. Variations in $\mathrm{Sr}, \mathrm{Ba}$, and $\mathrm{Mg}$ with $\mathrm{Ca}$ in Marcellus Formation produced waters. (a) Ca-normalized $\mathrm{Ba}$ concentrations show a generally coherent positive trend across Pennsylvania when plotted against $\mathrm{Ca}$-normalized $\mathrm{Sr}$, with the well waters from Greene County showing the most significant deviation from the trend. (b) Canormalized $\mathrm{Mg}$ concentrations do not exhibit a regional-scale trend, and are only weakly correlated within each well or region.

overlapping parts of this plot. In contrast, the $\mathrm{Mg} / \mathrm{Ca}$ ratio shows no systematic correlation with $\mathrm{Sr} / \mathrm{Ca}$ in the Marcellus Basin as a whole, although individual wells or regions sometimes have a weak correlation (Figure $3 \mathrm{~b}$ ). In addition, the $\mathrm{Mg} / \mathrm{Ca}$ ratio varies over a much smaller range of values (most within the molar ratio of $0.10-0.15$ ) compared to the range of $\mathrm{Ba} / \mathrm{Ca}$ and $\mathrm{Sr} / \mathrm{Ca}$ ratios. Thus $\mathrm{Mg}$ and $\mathrm{Ca}$ are relatively coherent across the basin, whereas $\mathrm{Ba}$, and to a lesser extent $\mathrm{Sr}$, may be affected more strongly by local variations.

The shifts in $\mathrm{Ba}$ and $\mathrm{Sr}$ across the basin are unlikely to result solely from variations in the shale barite $\left(\mathrm{BaSO}_{4}\right)$ content (and dissolution in hydraulic fracturing fluid), as the $\mathrm{Sr} / \mathrm{Ba}$ ratios in the produced waters are significantly higher than those expected for marine barite $(0.03-0.08) .^{25}$ The positive correlations of $\mathrm{Ba}$ with $\mathrm{Sr}$ at high $\mathrm{Sr} / \mathrm{Ba}$ ratios within individual wells argues against either introduction of $\mathrm{Ba}$ from drilling muds or removal of $\mathrm{Ba}$ by scaling (e.g., precipitation of $\mathrm{BaSO}_{4}$ in pipes and pore spaces) prior to extraction of the brine, as both of these should affect Ba much more strongly than Sr. The range of $\mathrm{Ba}$ and $\mathrm{Sr}$ concentrations in produced waters is most likely controlled by the combined dissolution of Ba- and Sr-rich minerals such as barite, witherite $\left(\mathrm{BaCO}_{3}\right)$, celestite $\left(\mathrm{SrSO}_{4}\right)$, and strontianite $\left(\mathrm{SrCO}_{3}\right)$, with the large differences in $\mathrm{Ba} / \mathrm{Ca}$ and $\mathrm{Sr} / \mathrm{Ca}$ among different regions reflecting the co-occurrence of these minerals at different abundances within shales of the Marcellus Formation. ${ }^{26}$

Sr Isotope Composition of Produced Waters. Strontium isotope ratios for Marcellus Formation produced waters are reported in Table 1 . Most produced waters fall within an $\varepsilon_{\mathrm{Sr}}^{\mathrm{SW}}$ range of +13.8 to +28.4 ; only the Westmoreland County wells deviate significantly, with an $\varepsilon_{\mathrm{Sr}}^{\mathrm{SW}}$ range of +39.8 to +41.6 . The total range of values for Marcellus produced waters, 
including the Westmoreland County samples, is quite restricted compared to possible water and rock with which they might interact. For example, Phanerozoic marine limestone falls within a range of -35 to $0,{ }^{27}$ and abandoned coal mine drainage outflows in western Pennsylvania can range from +35 to +140 (Table S1). Assuming that this wide range reflects typical ground and surface waters in the area, the $\varepsilon_{\mathrm{Sr}}^{\mathrm{SW}}$ values of Marcellus produced waters will likely be a distinguishing characteristic compared to local shallow groundwater or surface waters, or to other high-TDS waters.

In those sites where produced water was collected as it came out of the well, $\mathrm{Sr}$ (as well as other major elements not plotted) shows a clear trend of increasing concentration over time (Figure 4a). This apparently reflects progressive incorporation

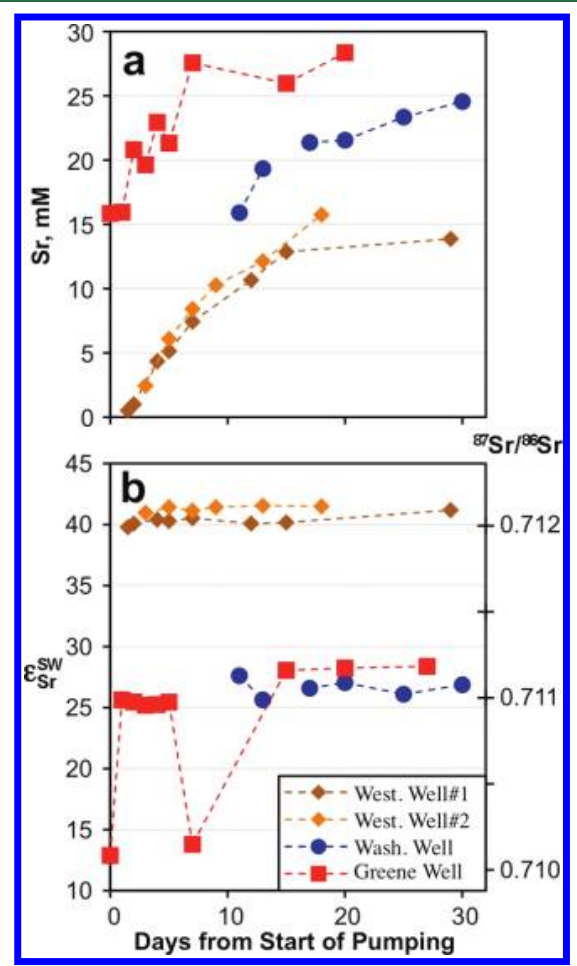

Figure 4. Variations in (a) Sr concentration and (b) $\varepsilon_{\mathrm{Sr}}^{\mathrm{SW}}$ (or ${ }^{87} \mathrm{Sr} /{ }^{86} \mathrm{Sr}$ ) plotted against the day of sample collection from the start of pumping. For the Greene County well (red squares) the point at day 0 is fracturing fluid. In all cases, the $\mathrm{Sr}$ concentration starts out lower and builds gradually to near a steady state value by 30 days. In contrast, the $\varepsilon_{\mathrm{Sr}}^{\mathrm{SW}}$ values appear to hit a steady state value within 5-10 days after initiation of pumping, reflecting the domination of Marcellus Formation salt or brine Sr to the overall Sr budget.

of salts or connate brines into the hydraulic fracturing fluid. In contrast, the produced waters reached a relatively constant $\varepsilon_{\mathrm{Sr}}^{\mathrm{SW}}$ value within the first two days of pumping (Figure $4 \mathrm{~b}$ ). It appears that in most cases, individual wells will produce waters with a very narrow range of $\varepsilon_{\mathrm{Sr}}^{\mathrm{SW}}$ values, most likely reaching a steady state value within the first few days after commencement of pumping.

Origin of TDS in Marcellus Produced Waters. The relatively narrow range of $\varepsilon_{\mathrm{Sr}}^{\mathrm{SW}}$ values of Marcellus Formation produced waters appears to be a distinguishing characteristic of these waters. Even when corrected for ${ }^{87} \mathrm{Rb}$ decay using available $\mathrm{Rb}$ concentration data, these values fall above the range of Middle Devonian seawater values, ${ }^{28}$ and in fact above any Phanerozoic seawater. ${ }^{27}$ If the salts or brines that are accessed by hydraulic fracturing are of marine origin, there must have been addition of radiogenic $\mathrm{Sr}\left({ }^{87} \mathrm{Sr}\right)$ prior or subsequent to incorporation into shales of the Marcellus Formation. Possible sources include the silicate portion of the shale itself (primarily clays), which should be relatively enriched in ${ }^{87} \mathrm{Sr}$, or basinal fluids that interacted with adjacent units before being incorporated (as brine or salt) in the Marcellus Formation. Given the relative homogeneity of the $\mathrm{Sr}$ isotope ratios over the $\sim 375 \mathrm{~km}$ distance represented by our sampling, large-scale fluid flow is a more likely source of the radiogenic $\mathrm{Sr}$ than localized incorporation of $\mathrm{Sr}$ from the shale. Evans ${ }^{29}$ documented multiple episodes of fluid migration in the Marcellus Formation based on fluid inclusion analysis. The somewhat bimodal distribution of values between the Westmoreland County waters and all of the others could reflect lithological variations within the Marcellus Formation, or variations in $\varepsilon_{\mathrm{Sr}}^{\mathrm{SW}}$ across the depositional basin. Additional produced water data combined with stratigraphic correlations will be required to characterize specific geographic trends in the $\mathrm{Sr}$ isotope ratios.

An important question in hydraulic fracturing is the extent to which the induced fractures remain in the target formation. If the fractures and hydraulic fracturing fluid come into contact with underlying or overlying formations, then additional solids could be introduced into the fluid. The Marcellus Formation in the sampling area is underlain by the Onondaga or Selinsgrove Limestone, and is overlain by shale and limestone members of the Hamilton Group. The Cherry Valley Limestone also divides upper and lower shale members of the Marcellus Formation. Unaltered marine limestones would normally have low $\varepsilon_{\mathrm{Sr}}^{\mathrm{SW}}$ values $(-35$ to 0$)$, while other shale units are likely to have variable $\varepsilon_{\mathrm{Sr}}^{\mathrm{SW}}$ values reflecting different sedimentary sources and histories. The narrow range of $\varepsilon_{\mathrm{Sr}}^{\mathrm{SW}}$ values from Marcellus Formation produced waters argues against significant incursions of hydraulic fracturing fluid into adjacent units. If the fluids did interact with adjacent units, the produced water would inherit the isotope signatures of brines or salts from those units, and it is highly unlikely that these would have isotopic compositions in the same narrow range as the $\varepsilon_{\mathrm{Sr}}^{\mathrm{SW}}$ values measured here. The argument against incursions into adjacent units is further bolstered by the apparently rapid attainment of steady state in $\varepsilon_{\mathrm{Sr}}^{\mathrm{SW}}$ achieved by produced waters. Interaction with units outside of the Marcellus gas production zones would likely cause greater variation than what is seen in the time series data (Figure $4 \mathrm{~b}$ ). The drop in $\varepsilon_{\mathrm{Sr}}^{\mathrm{SW}}$ on day 7 of the Greene County well production could reflect incorporation of solids from another source, either within or outside of the Marcellus Formation, but this isotope excursion was relatively short-lived. On the whole, the isotope variations in the Marcellus produced waters analyzed in this study are best explained by interactions with salts or brines within the shale itself.

Signatures of Marcellus Produced Waters. Elevated TDS alone is not always an effective tracer of produced water contributions, ${ }^{30}$ nor are variations in concentrations of dissolved chemical species, even those that are present at unusually high levels. Due to the low solubility of barite $\left(K_{\mathrm{sp}}=\right.$ $\left.10^{-10}\right)$, Ba cannot be considered a conservative element in aqueous systems, especially in cases where sulfate could be introduced from abandoned coal mine drainage (AMD). The very high concentrations of $\mathrm{Ba}$ in produced water may be stabilized by organic matter, excess $\mathrm{Cl}^{-}$, or the addition of antiscalants to hydraulic fracturing fluids, but dilution by 
freshwater is likely to cause significant precipitation of barite, which may be enhanced by further oxidation of $\mathrm{S}^{-}$to $\mathrm{SO}_{4}{ }^{2-} 31$ and the interaction of produced water with AMD. High $\mathrm{Na}$ and $\mathrm{Cl}$ concentrations are also characteristic of Marcellus produced waters. However, streams and rivers in populated areas often already contain significant concentrations of $\mathrm{Na}$ and $\mathrm{Cl}$ due to the use of road salt, leakage of septic systems, and wastewater outflows. ${ }^{32,33}$ In some cases, alkaline abandoned mine drainage can have $\mathrm{Na} / \mathrm{Ca}$ ratios equal to or higher than those of produced water (Table S1). A modest inflow of produced water would not be easily distinguishable or quantifiable under these circumstances. Moreover, brines from abandoned and leaking oil and gas wells from shallower formations commonly contain $\mathrm{Na}, \mathrm{Cl}, \mathrm{Ba}$, and $\mathrm{Sr}$ at concentrations comparable to those of Marcellus produced waters. ${ }^{34}$

Similarly, carbon isotopes alone are not always sufficient in distinguishing sources of high TDS. Isotopic fingerprinting using carbon isotopes can distinguish microbial from thermogenic methane. ${ }^{35-42}$ However, in some cases this method may not be able to distinguish between different stratigraphic sources of natural gas, such as between shallower natural gas sources tapped decades ago vs. a deep shale source in the Marcellus Formation, or between pipeline and storage gases and native thermogenic gas. Thermogenic methane from different units and ages can have similar methane isotopic signatures, resulting in ambiguous determination of the provenance of the carrier fluid. ${ }^{37,41-43}$

Because Marcellus produced waters have a restricted range of $\mathrm{Sr}$ isotope compositions, $\varepsilon_{\mathrm{Sr}}^{\mathrm{SW}}$ values could be a powerful tool for identifying possible sources of TDS introduced into streams or shallow aquifers. In the Appalachian region of the U.S., increases in dissolved solids to waterways can have several vectors, including road salt, drainage from inactive coal mines, leaching of coal fly ash disposal sites, and leakage of produced water from Marcellus Formation natural gas production. If the Sr concentration and isotope composition of two waters are known, then their mixing ratio can be precisely calculated, provided they have different $\varepsilon_{\mathrm{Sr}}^{\mathrm{SW}}$ values. The isotope ratio of the mixture is given by:

$$
R_{\mathrm{m}}=\frac{J_{1} C_{1} R_{1}+J_{2} C_{2} R_{2}}{J_{1} C_{1}+J_{2} C_{2}}
$$

where $R_{\mathrm{m}}$ is the isotope ratio of the final mixture (expressed as $\left.\varepsilon_{\mathrm{Sr}}^{\mathrm{SW}}\right), J_{1}$ and $J_{2}$ are the fluxes of the two endmember liquids prior to mixing, $C_{1}$ and $C_{2}$ are the $\mathrm{Sr}$ concentrations of the endmembers, and $R_{1}$ and $R_{2}$ are the $S r$ isotope compositions of the endmembers. This can be rearranged to give the flux ratio:

$$
\frac{J_{1}}{J_{2}}=\frac{C_{2} R_{2}+C_{2} R_{\mathrm{m}}}{C_{1} R_{\mathrm{m}}+C_{1} R_{1}}
$$

As can be seen from eq 1 , the isotope ratio of the mixture will be very sensitive to a component with a high $\mathrm{Sr}$ concentration, such as Marcellus produced waters. In a hypothetical case of produced water with $1000 \mathrm{mg} / \mathrm{L} \mathrm{Sr}$ and $\varepsilon_{\mathrm{Sr}}^{\mathrm{SW}}=+25$ mixing into a stream containing $0.5 \mathrm{mg} / \mathrm{L}$ Sr with $\varepsilon_{\mathrm{Sr}}^{\mathrm{SW}}=+50$, an addition of only $0.05 \%$ of the produced water would shift the stream ratio from +50 to +37.5 , well outside of measurement precision $(< \pm$ 0.2 ).

In western Pennsylvania, AMD has long been a source of pollution to local waterways. In several recent cases, an increase in TDS in local waterways has been attributed both to AMD and to leakage of produced waters. ${ }^{8-10}$ Cases such as these can potentially be resolved using $\mathrm{Sr}$ isotopes to identify the source of TDS. The Sr isotope composition of AMD from a variety of localities (Table S1) tends to be higher than that of produced water, and it also varies somewhat systematically with stratigraphic position of the mined coal (Figure 5). Although

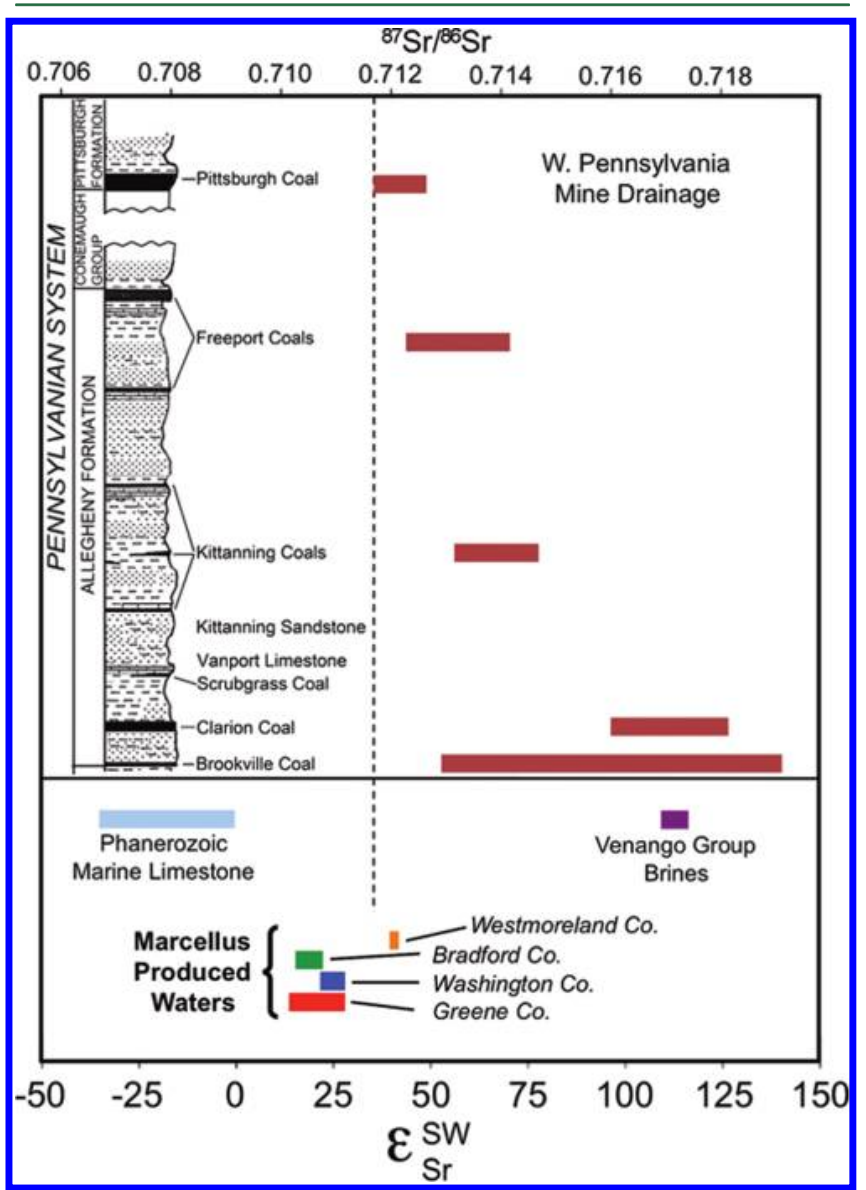

Figure 5. Strontium isotopic variations of Marcellus Formation produced waters compared to western Pennsylvania AMD, Phanerozoic limestone, ${ }^{27}$ and brines from the Venango Group, Pennsylvania. ${ }^{20}$ The Marcellus produced waters define a relatively tight field compared to other possible sources of $\mathrm{Sr}$ in the Marcellus natural gas production region. The isotopic composition of AMD waters appears to vary systematically with stratigraphic height, with the only overlap between AMD and produced waters coming from Pittsburgh coal $\mathrm{AMD}$ and produced waters from Westmoreland County. The tight clustering of Marcellus produced water values and large difference between these and other possible TDS sources indicate that $\mathrm{Sr}$ isotopes can be an effective tracer for produced water.

there is a limited degree of overlap in $\varepsilon_{\mathrm{Sr}}^{\mathrm{SW}}$ values, in most cases a clear distinction would be expected between produced water and AMD sources. The same is true of leakage from fly ash impoundments, which could have a range of $\varepsilon_{\mathrm{Sr}}^{\mathrm{SW}}$ values from -8 to $+80,{ }^{44,45}$ as well as very high $\mathrm{Ba}$ and Sr concentrations. ${ }^{46}$

The utility of $\mathrm{Sr}$ isotopes in identifying and quantifying sources of TDS to waterways can be further enhanced by combining $\varepsilon_{\mathrm{Sr}}^{\mathrm{SW}}$ with a distinguishing chemical parameter. This study indicates that $\mathrm{Sr} / \mathrm{Ca}$ ratios of produced water, while forming a basin wide trend, tend to vary from well to well (Figure 3a). Because both $\mathrm{Sr}$ and $\mathrm{Ca}$ are expected to be conservative tracers in these aqueous systems, combining $\mathrm{Sr} / \mathrm{Ca}$ ratios with $\varepsilon_{\mathrm{Sr}}^{\mathrm{SW}}$ values is likely to allow us to distinguish between sources in nearly all cases. To demonstrate, we 
calculated mixing equations for a hypothetical stream with an isotope ratio $\left(\varepsilon_{\mathrm{Sr}}^{\mathrm{SW}}=+35\right)$ between those of the Westmoreland County produced waters and all other produced waters, but with $\mathrm{Sr} / \mathrm{Ca}$ ratios typical of natural streams. Mixing curves were generated for this stream interacting with Marcellus produced waters, acid mine drainage from the Pittsburgh Coal Seam, and brines drawn from abandoned oil wells tapping the Venango Group (Figure 6). ${ }^{20}$ Produced waters from each well or region

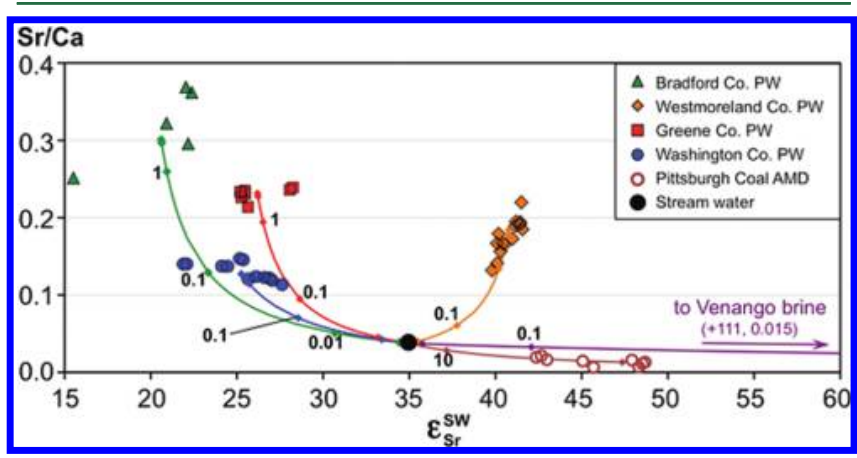

Figure 6. Mixing curves for a hypothetical stream being impacted by Marcellus Formation produced waters (all filled symbols indicated as "PW"), acid mine drainage (open circles), and Venango Group oil well brines (off scale). The produced waters are separated in $\mathrm{Sr} / \mathrm{Ca}-\varepsilon_{\mathrm{Sr}}^{\mathrm{SW}}$ space by geographic location. For each endmember, a weighted mean value is used to calculate the mixing curve, and individual samples are shown for comparison (except for Venango Group brines, which plot off scale to the right). The labeled tick marks on the curve indicate the percent flux of each endmember added to the hypothetical streamwater. A very small amount of produced water $(0.01-0.1 \%)$ added to the stream can produce large shifts in $\varepsilon_{\mathrm{Sr}}^{\mathrm{SW}}$ of $5-15$ epsilon units (note that typical measurement uncertainty is $<0.2$ epsilon units). A $1 \%$ addition of produced water will shift the stream isotopic composition to the $\varepsilon_{\mathrm{Sr}}^{\mathrm{SW}}$ of the produced water. Conversely, much larger amounts of AMD are required to shift the isotopic composition of the stream toward that endmember.

fall in a unique portion of $\mathrm{Sr} / \mathrm{Ca}-\varepsilon_{\mathrm{Sr}}^{\mathrm{SW}}$ space. Using the mean values as mixing endmembers, we can calculate the shift in $\mathrm{Sr} /$ $\mathrm{Ca}$ and $\varepsilon_{\mathrm{Sr}}^{\mathrm{SW}}$ resulting from addition of the produced waters or AMD to a stream; the labeled tick marks on the curves indicate the percentage of produced water or AMD required to generate the observed shift. In some cases, a flux equivalent to only $0.01 \%$ of the streamflow results in significant shifts of the streamwater isotope ratios, and a $0.1 \%$ addition can move the $\mathrm{Sr} / \mathrm{Ca}$ and $\varepsilon_{\mathrm{Sr}}^{\mathrm{SW}}$ of the stream up to halfway toward the produced water endmember values. In all cases, the stream $\varepsilon_{\mathrm{Sr}}^{\mathrm{SW}}$ value is completely dominated by produced water when the produced water flux reaches $1 \%$ of the streamflow. In contrast, much more AMD (>10\%) would be required to shift stream waters significantly toward AMD $\varepsilon_{\mathrm{Sr}}^{\mathrm{SW}}$ values. Because the AMD inflows in any given location are likely to be significantly different in $\varepsilon_{\mathrm{Sr}}^{\mathrm{SW}}$ from Marcellus produced waters, this method is likely to yield definitive evidence for the source of TDS contamination. In the event of a produced water spill, the amount of produced water or other contaminant entering the stream can be quantified. We note that the example shown in Figure 6 is for a stream with an isotopic composition not very different from Marcellus produced waters. Streams with $\varepsilon_{\mathrm{Sr}}^{\mathrm{SW}}$ values greater than about +50 , which are likely to be common in the Appalachian Basin, will be even more sensitive to influxes of Marcellus produced waters. Influxes of more than one contaminant into a stream would define a mixing field (rather than line) in a mixing diagram and could still be usefully quantified. Addition of other conservative tracers would allow extension of this simple mixing model to more complex cases of multiple contaminant sources.

An approach that integrates geochemistry, hydrogeology, and knowledge of historical background is critical to the successful remediation of existing water quality problems and the protection of water resources in the Appalachian Basin and other geologically and hydrochemically complex areas. These data suggest that the $\mathrm{Sr}$ isotope ratios constitute an extremely sensitive tracer with strong potential as a tool for verification of safe water disposal, and can be used to determine the origin of TDS in surface and ground waters affected by multiple sources as well as quantify mixing between them.

\section{ASSOCIATED CONTENT}

\section{S Supporting Information}

Table S1, containing major element chemistry, $\mathrm{pH}$, alkalinity, and $\mathrm{Sr}$ isotope ratios for coal mine drainage outflows in western Pennsylvania. This information is available free of charge via the Internet at http://pubs.acs.org/.

\section{AUTHOR INFORMATION}

\section{Corresponding Author}

*Phone: 412-624-8883; fax: 412-624-3914; e-mail: bstewart@ pitt.edu.

\section{Notes}

The authors declare no competing financial interest.

\section{ACKNOWLEDGMENTS}

We thank Robert Hedin and Ted Weaver for assistance in sampling AMD waters and information about local geology, and Radisav Vidic and Elise Barbot for access to Westmoreland County samples and associated NETL geochemical data. Detailed and helpful reviews by J. McIntosh, S. Osborn, and an anonymous reviewer greatly improved the manuscript. This technical effort was performed in support of the National Energy Technology Laboratory's ongoing research under the RES contract DE-FE0004000, and was partially supported by the NETL-Oak Ridge Institute for Science and Education Faculty Research Program (R.C.C. and B.W.S.).

\section{REFERENCES}

(1) Modern Shale Gas Development in the United States: A Primer; United States Department of Energy Office of Fossil Energy: Oklahoma City, OK, 2009; http://www.netl.doe.gov/technologies/ oil-gas/publications/epreports/shale_gas_primer_2009.pdf.

(2) Kerr, R. A. Natural gas from shale bursts onto the scene. Science 2010, 328 (5986), 1624-1626.

(3) 2009 Year End Workload Reports; Pennsylvania Department of Environmental Protection: Harrisburg, PA, 2010; http://files.dep.state. pa.us/OilGas/BOGM/BOGMPortalFiles/OilGasReports/2009/ 2009_Year_End_Reports.pdf.

(4) Blauch, M. E.; Myers, R. R.; Moore, T. R.; Lipinski, B. A., Marcellus Shale post-frac flowback waters - Where is all the salt coming from and what are the implications? 2009 Society of Petroleum Engineers Eastern Regional Meeting, SPE 125740, Charleston, WV, 2009; pp 1-20.

(5) National Primary Drinking Water Regulations; EPA 816-F-09-004; United States Environmental Protection Agency: Washington, DC, 2009; http://water.epa.gov/drink/contaminants/upload/mcl-2.pdf.

(6) Final Report: Water Management Technologies Used by Marcellus Shale Gas Producers; United States Department of Energy-NETL- 
Argonne National Lab: Argonne, IL, 2010; http://www.evs.anl.gov/ pub/dsp_detail.cfm?PubID=2537.

(7) Kargbo, D. M.; Wilhelm, R. G.; Campbell, D. J. Natural gas plays in the Marcellus Shale: Challenges and potential opportunities. Environ. Sci. Technol. 2010, 44 (15), 5679-5684.

(8) Pennsylvania Nonpoint Source Management Program FFY2008 Annual Report; Pennsylvania Department of Environmental Protection: Harrisburg, PA, 2009; http://www.epa.gov/reg3wapd/pdf/pdf nps/nps_annualreports/2008/FY2008_PA-Final-Annual-Report.pdf.

(9) Renner, R. Spate of gas drilling leaks raises Marcellus concerns. Environ. Sci. Technol. 2009, 43 (20), 7599.

(10) Press Release: PA Fish and Boat Commission sues Consol Energy over Dunkard Creek environmental disaster; Pennsylvania Fish and Boat Commission: Harrisburg, PA, 2011; http://www.fish.state.pa.us/ newsreleases/2011press/dunkard-sue.htm.

(11) Supplemental Generic Environmental Impact Statement on the Oil, Gas and Solution Mining Regulatory Program; New York State Department of Environmental Conservation: Albany, NY, 2011; http://www.dec.ny.gov/energy/47554.html.

(12) Bayless, E. R.; Bullen, T. D.; Fitzpatrick, J. A. Use of ${ }^{87} \mathrm{Sr} /{ }^{86} \mathrm{Sr}$ and $\delta^{11} \mathrm{~B}$ to identify slag-affected sediment in southern Lake Michigan. Environ. Sci. Technol. 2004, 38 (5), 1330-1337.

(13) Leung, C.-M.; Jiao, J. J. Use of strontium isotopes to identify buried water main leakage into groundwater in a highly urbanized coastal area. Environ. Sci. Technol. 2006, 40 (21), 6575-6579.

(14) Brinck, E. L.; Frost, C. D. Detecting infiltration and impacts of introduced water using strontium isotopes. Ground Water 2007, 45 (5), 554-568.

(15) Jiang, Y.; Wu, Y.; Yuan, D. Human impacts on karst groundwater contamination deduced by coupled nitrogen with strontium isotopes in the Nandong Underground River System in Yunan, China. Environ. Sci. Technol. 2009, 43 (20), 7676-7683.

(16) Hamel, B. L.; Stewart, B. W.; Kim, A. G. Tracing the interaction of acid mine drainage with coal utilization byproducts in a grouted mine: Strontium isotope study of the inactive Omega Coal Mine, West Virginia (USA). Appl. Geochem. 2010, 25 (2), 212-223.

(17) Christian, L. N.; Banner, J. L.; Mack, L. E. Sr isotopes as tracers of anthropogenic influences on stream water in the Austin, Texas, area. Chem. Geol. 2011, 282 (3/4), 84-97.

(18) Barnaby, R. J.; Oetting, G. C.; Gao, G. Strontium isotopic signatures of oil-field waters: Applications for reservoir characterization. Am. Assoc. Pet. Geol. Bull. 2004, 88 (12), 1677-1704.

(19) Peterman, Z. E.; Thamke, J. N.; Futa, K.; Oliver, T. A. Strontium isotope detection of brine contamination in the East Poplar oil field, Montana. U.S.G.S. Open-File Rep. 2010, 2010-1326, 1-20.

(20) Chapman, E. C.; Capo, R. C.; Stewart, B. W.; Hedin, R. S.; Weaver, T. J.; Edenborn, H. M. Strontium isotope quantification of siderite, brine, and acid mine drainage contributions to abandoned gas well discharges in the Appalachian Plateau. Appl. Geochem. 2012, submitted.

(21) Steuber, A. M.; Walter, L. M. Origin and chemical evolution of formation waters from Silurian-Devonian strata in the Illinois basin, USA. Geochim. Cosmochim. Acta 1991, 55 (1), 309-325.

(22) Rowan, E. L.; de Marsily, G. Infiltration of Late Palaeozoic evaporative brines in the Reelfoot rift: a possible salt source for Illinois basin formation waters and MVT mineralizing fluids. Pet. Geosci. 2001, 7 (3), 269-279.

(23) McIntosh, J. C.; Walter, L. M.; Martini, A. M. Extensive microbial modification of formation water geochemistry: Case study from a Midcontinent sedimentary basin, United States. Geol. Soc. Am. Bull. 2004, 116 (5/6), 743-759.

(24) Rowan, E. L. Inorganic chemistry of produced water in the Appalachian Basin. In EPA Technical Workshop for the Hydraulic Fracturing Study; Arlington, VA, 2011; pp 10-13.

(25) Paytan, A.; Averyt, K.; Faul, K.; Gray, E.; Thomas, E. Barite accumulation, ocean productivity, and $\mathrm{Sr} / \mathrm{Ba}$ in Barite across the Paleocene-Eocene Thermal Maximum. Geology 2007, 35 (12), 11391142.
(26) Siegel, D. I.; Chamberlain, S. C.; Dossert, W. P. The isotopic and chemical evolution of mineralization in septarian concretions: Evidence for episodic paleohydrogeologic methanogenesis. Geol. Soc. Am. Bull. 1987, 99 (3), 385-394.

(27) Burke, W. H.; Denison, R. E.; Hetherington, E. A.; Koepnick, R. B.; Nelson, H. F.; Otto, J. B. Variation of seawater ${ }^{87} \mathrm{Sr} /{ }^{86} \mathrm{Sr}$ throughout Phanerozoic time. Geology 1982, 10 (10), 516-519.

(28) Diener, A.; Ebneth, S.; Veizer, J.; Buhl, D. Strontium isotope stratigraphy of the Middle Devonian: Brachiopods and conodonts. Geochim. Cosmochim. Acta 1996, 60 (4), 639-652.

(29) Evans, M. A. Fluid inclusions in veins from the Middle Devonian shales: A record of deformation conditions and fluid evolution in the Appalachian Plateau. Geol. Soc. Am. Bull. 1995, 107 (3), 327-339.

(30) Frost, C. D.; Brinck, E. L.; Mailloux, J.; Sharma, S.; Campbell, C. E.; Carter, S. A.; Pearson, B. N. Innovative approaches for tracing water co-produced with coalbed natural gas: Applications of strontium and carbon isotopes of produced water in the Powder River Basin, Wyoming and Montana. In Coalbed Natural Gas: Energy and Environment; Reddy, K. J., Ed.; Nova Publishers: Hauppauge, NY, 2010; pp 59-80.

(31) Blount, C. W. Barites solubilities and thermodynamic quantities up to $300^{\circ} \mathrm{C}$ and $1400 \mathrm{bar}$. Am. Miner. 1977, 62 (9/10), 942-957.

(32) Berner, E. K.; Berner, R. A. Global Environment: Water, Air, and Geochemical Cycles; Prentice Hall: Upper Saddle River, NJ, 1996.

(33) Mullaney, J. R; Lorenz, D. L.; Arntson, A. D. Chloride in groundwater and surface water in areas underlain by the glacial aquifer system, northern United States. USGS Sci. Invest. Rep. 2009, 5086, 141.

(34) Dresel, P. E.; Rose, A. W. Chemistry and origin of oil and gas well brines in western Pennsylvania. Pennsylvania Geol. Surv. Open-File Rep. 2010, 10-01.0, 1-48.

(35) Schoell, M. The hydrogen and carbon isotopic composition of methane from natural gases of various origins. Geochim. Cosmochim. Acta 1980, 44 (5), 649-661.

(36) Schoell, M. Genetic characterization of natural gases. Am. Assoc. Pet. Geol. Bull. 1983, 67 (12), 2225-2238.

(37) Baldassare, F. J.; Laughrey, C. D. Identifying the sources of stray methane by using geochemical and isotopic fingerprinting. Environ. Geosci. 1997, 4 (2), 85-94.

(38) Kaplan, I. R.; Galperin, Y.; Lu, S.-T.; Lee, R.-P. Forensic environmental geochemistry: differentiation of fuel-types, their sources and release time. Org. Geochem. 1997, 27 (5/6), 289-317.

(39) Martini, A. M.; Walter, L. M.; McIntosh, J. C. Identification of microbial and thermogenic gas components from Upper Devonian black shale cores, Illinois and Michigan basins. Am. Assoc. Pet. Geol. Bull. 2008, 92 (3), 327-339.

(40) Osborn, S. G.; McIntosh, J. C. Chemical and isotopic tracers of the contribution of microbial gas in Devonian organic-rich shales and reservoir sandstones, northern Appalachian Basin. Appl. Geochem. 2010, 25 (3), 456-471.

(41) Révész, K. M.; Breen, K. J.; Baldassare, F. J.; Burruss, R. C. Carbon and hydrogen isotopic evidence for the origin of combustible gases in water-supply wells in north-central Pennsylvania. Appl. Geochem. 2010, 25 (12), 1845-1859.

(42) Osborn, S. G.; Vengosh, A.; Warner, N. R.; Jackson, R. B. Methane contamination of drinking water accompanying gas-well drilling and hydraulic fracturing. Proc. Nat. Acad. Sci. 2011, 108 (20), $8172-8176$

(43) Saba, T.; Orzechowski, M. Letter: Lack of data to support a relationship between methane contamination of drinking water wells and hydraulic fracturing. Proc. Nat. Acad. Sci. 2011, 108 (37), E663.

(44) Spivak-Birndorf, L.; Stewart, B. W.; Capo, R. C.; Chapman, E. C.; Schroeder, K. T.; Brubaker, T. M. Strontium isotope study of coal utilization by-products interacting with environmental waters. $J$. Environ. Qual. 2012, 41 (1), 144-154.

(45) Brubaker, T. M.; Stewart, B. W.; Capo, R. C.; Schroeder, K. T.; Chapman, E. C.; Spivak-Birndorf, L. J.; Vesper, D. J.; Cardone, C. R.; Rohar, P. C. Coal fly ash interaction with environmental fluids: 
Geochemical and strontium isotope results from combined column and batch leaching experiments. Appl. Geochem. 2012, submitted.

(46) Querol, X.; Umaña, J. C.; Alastuey, A.; Ayora, C.; Lopez-Soler, A.; Plana, F. Extraction of soluble major and trace elements from fly ash in open and closed leaching systems. Fuel 2001, 80 (6), 801-813. 